\title{
O livro de imagem e a inclusão da criança surda na biblioteca escolar
}

Ana Paula Pereira

http://orcid.org/0000-0003-2635-9014

André Luís Onório Coneglian

http://orcid.org/0000-0002-4172-5521

Sueli Bortolin ${ }^{I I I}$

http://orcid.org/0000-0001-7411-2716

Adriana Rosecler Alcará ${ }^{I V}$

http://orcid.org/0000-0003-4639-0967

${ }^{I}$ Universidade Estadual de Londrina, PR, Brasil.

Doutoranda no Programa de Pós-Graduação em Ciência da Informação da Universidade Estadual de Londrina (PPGCI/UEL).

${ }^{I I}$ Universidade Estadual de Londrina, PR, Brasil.

Doutor em Ciência da Informação pela Universidade Estadual Paulista/Marília-SP. Professor no Departamento de Letras/Espanhol, Universidade Estadual do Paraná (UNESPAR), campus de União da Vitória-PR.

${ }^{I I I}$ Universidade Estadual de Londrina, PR, Brasil.

Doutora em Ciência da Informação pela Universidade Estadual Paulista/MaríliaSP. Professora no Programa de Pós-Graduação em Ciência da Informação da Universidade Estadual de Londrina (PPGCI/UEL).

${ }^{I V}$ Universidade Estadual de Londrina, PR, Brasil.

Doutora em Psicologia pela Universidade São Francisco (USF/SP). Professora no Programa de Pós-Graduação em Ciência da Informação da Universidade Estadual de Londrina (PPGCI/UEL)

http://dx.doi.org/10.1590/1981-5344/4179 
O objetivo do artigo é refletir sobre o processo de leitura e de escrita dos surdos, evidenciando o seu impacto nas ações do mediador da leitura na biblioteca escolar e apresentar o livro de imagem como um recurso eficiente para o fluir da leitura dos surdos. Defende que a surdez ultrapassa a constatação de uma deficiência e se caracteriza por uma diferença. Nesse sentido, foi essencial abordar nesse trabalho a Língua de Sinais, uma Língua espaço-motora-visual que mediará o pensamento e a comunicação do sujeito surdo, pois seu pensamento se processa de modo diferente dos ouvintes, isto é, por sinais. Como procedimentos metodológicos, o texto foi construído com base em pesquisa bibliográfica, nas áreas da Educação, Biblioteconomia e Ciência da Informação, sem delimitação temporal em virtude da escassez de produção científica, especialmente nas duas últimas áreas. Salienta que a biblioteca escolar precisa valorizar a leitura da literatura infantil, a qual pode ser fonte de diversidade e de multiplicidade, sendo fundamental a ação dos mediadores da leitura no fortalecimento das práticas leitoras. Detecta que, de modo geral, a biblioteca escolar não se apresenta como local acessível e inclusivo e, por essa razão, não faz parte da vida dos surdos; bem como a atitude dos mediadores diante da criança surda não fortalece o sentimento de pertença e a apropriação dos diversos textos literários. Conclui que o livro de imagem, com seu vocabulário receptivo visual, tende a contribuir para a inserção da criança surda no universo da leitura e favorecer a fruição, o prazer e o aprender por meio da literatura.

Palavras-chave: Leitor surdo. Livro de imagem. Mediador da leitura. Biblioteca escolar acessível.

\section{The picture book and the inclusion of deaf children in the school library}

The objective of the article is to reflect on the reading and writing process of the deaf, showing its impact on the actions of the reading mediator in the school library and 
to present the picture book as an efficient resource for the reading flow of the deaf. He argues that deafness goes beyond the finding of a disability and stands out for a difference. In this sense, it was essential to address in this work the Sign Language, a space-motor-visual language that will mediate the thinking and communication of the deaf subject, as his thinking is processed differently from the listeners, that is, through signs. Methodological procedures, the text was built based on bibliographical research, in the areas of Education, Librarianship and Information Science, without temporal delimitation due to the scarcity of scientific production, especially in the last two areas. It emphasizes that the school library needs to value the reading of children's literature, which can be a source of diversity and multiplicity, and the action of reading mediators is essential to strengthen reading practices. Detects that, in general, a school library does not present itself as an accessible and inclusive place and, for this reason, it is not part of the life of the deaf; as well as the attitude of the mediators towards the deaf child does not strengthen the feeling of belonging and the appropriation of the various literary texts. It concludes that the picture book, with its visual receptive vocabulary, tends to contribute to the insertion of deaf children in the universe of reading and to favor enjoyment, pleasure and learning through literature.

Keywords: Deaf reader. Picture book. Reading mediator. Accessible school library.

Recebido em 29.10.2019 Aceito em 23.06.2021

\section{Introdução}

A chamada "literatura surda" que preconiza o empoderamento de autores surdos, com personagens surdos e com comunicação fortemente visual em Língua de Sinais e/ou em signwriting ${ }^{l}$ ainda não é um material

\footnotetext{
${ }^{1}$ SignWriting-é "[...] um sistema americano de escrita das LS criado por Sutton em 1981 definição em português e inglês, desenho do sinal e desenho ilustrativo." (BARROS, 2008, p.72).
} 
de fácil aquisição. Como alternativa propõe-se a utilização do livro de imagem, também denominado de livro sem texto ou narrativa visual no incentivo à leitura pelos leitores surdos. Por observação e relatos de experiências é possível afirmar que ele pode contribuir nos momentos de mediação da leitura para o público escolar. (PAIVA, 2014; COSTA; SANTOS NETO, 2019).

O livro de imagem desperta a emoção, a sensibilidade, a imaginação e favorece a socialização, tornando-se para a criança surda um dispositivo precioso na apropriação da leitura, da literatura e da informação.Portanto, considerar o potencial do livro de imagem e a situação lamentável de poucas iniciativas na Biblioteconomia em prol de uma biblioteca escolar acessível, inclusiva e acolhedora, é fundamental para"[...] garantir o acesso à informação, mas também formar um espaço agradável e acolhedor, no qual minorias sociais e linguísticas possam exercer a sua cidadania e lazer."(PEREIRA, 2018, p.03).

O objetivo do artigo foi propiciar reflexões acerca do uso do livro de imagem no incentivo à leitura para os leitores surdos. Optou-se em promover inicialmente discussões quanto ao processo de leitura e de escrita dos surdos e, posteriormente, focou-se na biblioteca escolar como dispositivo e nos mediadores, como possibilidade de aproximação com a literatura.

Nesse sentido, esta investigação, de abordagem qualitativa, foi desenvolvida por meio de pesquisa bibliográfica, nas áreas da Educação, Biblioteconomia e Ciência da Informação, principalmente nas bases de dados Scielo, Base de Dados de Periódicos em Ciência da Informação (BRAPCI) e Google Acadêmico. Lima e Mioto (2007, p.44) consideram esse gênero de pesquisa "[...] importante na produção do conhecimento científico capaz de gerar, especialmente em temas pouco explorados, a postulação de hipóteses ou interpretações que servirão de ponto de partida para outras pesquisas."

Para que se possa alcançar o objetivo proposto, este estudo foi estruturado da seguinte forma, essa introdução; em seguida nas subseções dois e três denominadas $A$ criança surda e a leitura e $A$ criança surda e a escrita visou-se conhecer com detalhes os atos de ler e escrever, que se processam de modos diferentes na criança surda. $\mathrm{Na}$ subseção quatro aborda-se a Biblioteca acessível. Os Mediadores e o livro de imagem são valorizados na seção de número cinco e, na subseção seis apresenta-se as considerações finais na perspectiva de incompletude, visto que ainda há muito a ser discutido e partilhado entre Educação, Biblioteconomia e áreas da saúde que venham ampliar o conhecimento e entendimento dos usuários surdos. 


\section{A criança surda e a leitura}

Inicialmente, é necessário esclarecer os termos e os seus usos adequados e inadequados. "Deficiente Auditivo" é um termo adequado para uso na área médica e fonoaudiológica, pois refere-se aos graus de perda da audição humana. "Surdo" é um termo adequado de autodenominação e, preferencialmente, utilizado pela comunidade surda; termo com denotação mais social e antropológica. (SKLIAR, 1998; 2000).

Os termos inadequados são "surdo-mudo" e "mudinho", o primeiro ainda muito utilizado no senso comum, atribui-se a ele o fato do sujeito surdo não ouvir, portanto, não poder vocalizar, o que não é real, pois o sujeito surdo, mesmo não ouvindo, pode emitir sons, pode aprender a leitura orofacial com profissionais habilitados para tanto. "Mudinho" tem conotação mais pejorativa e, durante décadas, denominou vários sujeitos deficientes auditivos/surdos como alcunha e até mesmo substituindo o nome desses indivíduos.

Portanto, a concepção de surdez e surdo para o artigo, é entendida como uma diferença e não uma deficiência e "[...] deve ser definida positivamente pela presença da Língua de Sinais e por tudo aquilo em que ela implica para a constituição de identidade e cultura próprias." (CAPOVILLA et al., 2001, p.1507).

Para tanto, a criança surda precisa desenvolver habilidades que permitam a ela se apropriar da informação por meio da leitura, sendo assim o domínio da Língua de Sinais é essencial. Destaca-se que esse domínio não é apenas para os surdos, mas também para os ouvintes, isto é, para os demais atores sociais que se comunicam com a palavra falada, permitindo que os surdos tenham outros interlocutores.

Segundo Guarinello (2007, p.54) estudos apontam que os surdos que nascem em família com pais surdos: "[...] estão mais bem preparados para enfrentar a etapa escolar e apresentam melhor desempenho na leitura e na escrita, já que foram expostos a uma Língua comum a si e a seus pais, ou seja, a Língua de Sinais."

Uma mudança nesse sentido exige: a compreensão, por parte do ouvinte, de que o código alfabético não atua da mesma maneira para o surdo porque ele não acessa aos sons da fala. Consequentemente, sua comunicação e o seu pensamento se processam de forma diferente, isto é, por sinais. Neste caso, "[...] enquanto a criança ouvinte recorre [...] a forma de sua fala interna, a Surda tende a recorrer às propriedades [...] a forma de sua sinalização interna". (CAPOVILLA et al., 2001, p.1492). A criança surda irá recorrer ao seu "banco de dados léxico", que é formado essencialmente por sinais, e em fase de aprendizagem, esse banco de dados léxico a auxiliará a aprender novos temas (portanto, novos sinais), 
considerando que a criança surda tenha outro interlocutor em Língua de Sinais.

O processo ocorre diferente quando estiver frente ao material escrito em Língua Portuguesa. Essa criança precisará associar a palavra escrita (unidade mínima com significado) a um léxico (também com um significado) da Língua de Sinais para fazer sentido (o sinal interno). Com um processo de ensino-aprendizagem adequado, a criança surda logo incorporará também esse outro banco de dados léxico (Português escrito) atribuindo significado, sem necessariamente passar pela "tradução" correspondente na Língua de Sinais.

A criança ouvinte, por sua vez, se apropria da fala - aquela que irá subsidiar a aprendizagem da leitura e da escrita em idade escolar (da Língua que ouve desde que nasceu e fala já há algum tempo), enquanto o mesmo não acontece com a criança surda que utiliza a Língua de Sinais para realizar os atos de ler e escrever (numa língua que não ouve).

A aquisição da linguagem escrita pela criança surda ocorre apoiada pela visão. Entretanto, para ela o "[...] vocabulário receptivo visual [...] contribui pouco para aumentar a compreensão direta do significado da leitura alfabética [...]." (CAPOVILLA et al., 2001, p.1505).

A título de exemplo, as crianças que escutam, dificilmente farão troca ou confusão entre o significado das palavras ALMOÇO e ABRAÇO. Porém, para um estudante surdo, que se apoia exclusivamente ao que Capovilla et al.(2001)chamaram de "vocabulário receptivo visual", a criança trocou em Libras, os sinais: para a palavra ALMOÇO, sinalizou ABRAÇO.Ou seja, apoiando-se apenas na visão das palavras (AbrAÇO, AlmoÇO, AbraÇO, AlmoÇO), a criança surda leu "abraço" onde estava escrito "almoço", pois ortográfica e visualmente o início e término das palavras são similares.

De maneira geral, os mediadores da biblioteca escolar, em sua maioria ouvintes, tem dificuldade de compreender a forma de leitura dos surdos, mas, talvez o mais complexo seja conceber que a escrita deles difere do estudante ouvinte, conforme será abordado na seção 3 deste artigo. "Há um abismo informacional e atitudinal entre ouvintes e surdos, o qual ultrapassa o despreparo diante do desconhecido, para a omissão e o descaso diante da invisibilidade da diferença sensorial auditiva em relação à condição ouvinte majoritária." (CORRADI, 2011, p.21).

Em face disso, pode-se "[...]imaginar quão difíceis são a leitura e a escrita do código alfabético para criança surda, que simplesmente não tem acesso à fonologia relevante à leitura e a escrita do código alfabético." (CAPOVILLA et al., 2001, p.1504). Nesse sentido, é importante salientar que 
[...] a criança Surda tende a passar pelos mesmos estágios de leitura e escrita que a ouvinte. [...] a criança Surda abandona a mera memorização global e passa a ancorar a leitura e a escrita alfabéticas na Língua de Sinais, que é, para ela, a Língua primária com que se comunica com os outros e consigo mesma. O problema, no entanto, reside na natureza do código alfabético que, ao mapear os sons da fala, naturalmente reforça e premia a tendência da criança ouvinte de ler e escrever da forma como ela fala, mas é incapaz de reforçar e premiar do mesmo modo a tendência da criança Surda de ler e escrever da forma como ela sinaliza. (CAPOVILLA et al., 2001, p.1504).

Na criança ouvinte, a fala apoia a leitura e a escrita, porém, para a criança surda isso não ocorre na mesma forma. Exatamente pelo fato de a criança ouvinte ler e escrever a Língua que fala e pensa. Para a criança surda, como dito anteriormente, a Língua de Sinais é a Língua de pensamento. Ao ler e escrever em Português, ela precisará fazer, mentalmente, o processo de tradução para a Língua de Sinais.

No entanto, é preciso lembrar que "[...] a necessidade de adquirir informação sobre o mundo ao redor, não é menor para as crianças surdas." (FREEMAN; CARBIN; BOESE, 1999, p.283). Pelo contrário, a leitura para as crianças (surdas ou ouvintes) "[...] contribui para compreender os próprios problemas, estimular a imaginação [...] desenvolver potencialidades, estimular sua curiosidade, inquietar-se por tudo que é novo." (DOMINGUES et al., 2008, p.07).

Convém ressaltar que a recepção de um texto apesar de sofrer influências externas, é peculiar a cada indivíduo e pode "[...] provocar reações diversas em indivíduos diferentes, em função de suas experiências, de sua condição social ou de seu poder de percepção e de entendimento." (DOMINGUES et al., 2008, p.07).

Segundo Castro (2015, p.283) na atualidade a criança foi "[...] elevada ao status de cliente, isto é, um sujeito que compra, gasta, consome e, sobretudo, é muito exigente." Nesse sentido, uma obra literária e o imaginário que ela desperta pode liberar e"[...]extrair dos alunos sentimentos reprimidos, apaziguar emoções e [...]ter uma maior interação com o meio em que vive." (DOMINGUES et al., 2008, p.08).

Para que o mediador (seja ele professor ou bibliotecário) efetivamente contribua com a autonomia e independência da criança surda, além do seu processo de leitura é necessário que ele compreenda a construção da comunicação escrita dessa criança. A seguir apresenta-se algumas reflexões a respeito disso. 


\section{A criança surda e a escrita}

A compreensão do processo de educação formal dos estudantes surdos, em especial, na escrita é influenciada por diversos fatores. Isso porque, nela estão envolvidos aspectos fisiológicos, psicológicos e pedagógicos que exigem, dentro da escola, um redimensionamento dos aspectos conceituais, metodológicos e avaliativos que envolvem 0 processo de ensino e aprendizagem da leitura e da escrita para os sujeitos surdos. Esse contexto torna a atuação dos mediadores de leitura ainda mais desafiadora. Nesse sentido, a família, os professores, bibliotecários e toda a comunidade escolar, sejam gestores, coordenadores ou pedagogos precisam estar informados dos requisitos necessários ao processo de aprendizagem dos surdos.

Bortolin, Coelho e Araújo (2017, p.09-10) afirmam que "[...] os profissionais que atuam na biblioteca infantil necessitam ter conhecimento do processo de escrita[dos surdos], que é diferenciado daquele do sujeito ouvinte." Para tornar compreensiva a afirmativa, um tanto enfática, as autoras destacam que: "[...] em uma oficina de produção de textos devem-se considerar possíveis ausências ou troca de artigos, elementos de ligação, gênero, verbos entre [outros] fatores gramaticais." (BORTOLIN; COELHO; ARAÚJO, 2017, p.10).

A escola e sua biblioteca são agentes formadores, porém, ao conceber "[...] a linguagem e as atividades de leitura e escrita [...] como algo passível de ser aprendido por meio de exercícios mecânicos e descontextualizados, contribui para que os problemas dos surdos com a escrita aumentem." (GUARINELLO, 2007, p.55).

Na obra Libras? Que língua é essa? Crenças e preconceitos em torno da Língua de Sinais e da realidade surda, Gesser (2009) a dividiu em três capítulos (1. A Língua de Sinais; 2. O surdo e 3. A surdez) e subdividiu os capítulos em tópicos questionadores, imbricados com mitos e crenças e senso comum, os quais passa a refutar, embasados em pesquisas científicas.

Utiliza-se aqui duas dessas questões para problematizar e refletir acerca da apropriação da Língua escrita pelo indivíduo surdo: "O surdo tem dificuldade de escrever porque não sabe falar a Língua oral?" e "O uso da Língua de Sinais atrapalha a aprendizagem da Língua oral?" (GESSER, 2009, p.56-59).

Segundo a autora, sobre a primeira questão "[...] é uma crença nociva e levanta várias questões sobre as quais é preciso refletir" (GESSER, 2009). Prossegue, estabelecendo que "[...] a escrita é uma habilidade cognitiva que demanda esforço de todos (surdos, ouvintes, ricos, pobres, homens, mulheres...) e geralmente é desenvolvida quando se recebe instrução formal." (GESSER, 2009, p.56). 
Desse modo, o ensino da Língua Portuguesa, a Língua majoritária em solo brasileiro "[...] deve ser pautada no ensino formal em sua modalidade escrita" (GESSSER, 2009, p.59), o que exige o reconhecimento por parte do professor da disciplina que as habilidades cognitivas de leitura e de escrita são distintas e podem ser ensinadas sem a intermediação da voz (da oralidade).Para Guarinello e Gregolin (2005) diferentes profissionais se dedicam aos estudos da surdez, porém em suas publicações

[...] destacavam as dificuldades e as diferentes construções escritas dos surdos; alguns se detinham na sua escrita considerada "atípica"; outros na interferência da Língua de Sinais nas construções escritas; outros na condição da surdez, e havia, ainda, os que relacionavam a escrita a técnicas pedagógicas inadequadas. Porém, poucas eram as propostas para o desenvolvimento da escrita [...] muitos surdos continuam com dificuldades para aprender a ler e a escrever, e um grande número deles não tem acesso a práticas discursivas significativas que propiciem o domínio da linguagem escrita. (GUARINELLO; GREGOLIN, 2005, p.135).

Dito de outro modo, os indivíduos surdos podem aprender a ler e escrever a Língua Portuguesa sem oralizá-la. A leitura "silenciosa", mental, num processo cognitivo de inter-relação com a Língua de Sinais e aprendizagem da escrita ortográfica, visualmente, relacionando cada unidade visual (a palavra) a um outro signo linguístico (em Língua de Sinais).

Pessoas ouvintes, ao iniciar o processo de aprendizagem de uma língua estrangeira - Russo, por exemplo - podem optar por aprender ler e escrever Russo, sem necessariamente aprender a pronunciar (oralizar) Russo. Para as pessoas surdas, o processo de aprendizagem da Língua Portuguesa é similar: aprenderam a ler e escrever o Português sem pronunciá-lo.No entanto, em muitos casos a escrita produzida por um surdo não corresponde a escrita exigida dos ouvintes. A seguir temos um exemplo de escrita citada por Guarinello e Gregolin (2005, p.138) no artigo intitulado As produções escritas de sujeitos surdos:

Quadro 1 - Exemplo de texto produzido por um surdo

1 - Um Acontecer,minha irmã apartamento, o ladrão pega um ferro forçar, a porta quebrou abril,

2 - ele pulo na dentro casa andou viu todos cosia,

3 - ele robrou TV. Radio, cd 70.

4 - Karina e Terezinha chegou para apartamento, 


$$
\begin{aligned}
& 5 \text { - elas viu subiu Tv, rádio, cd 70, } \\
& 6 \text { - ela ficou chora, chora, a Terezinha ficou nervosa. } \\
& 7 \text { - Ela falou para namorada também eu. }
\end{aligned}
$$

Fonte: Adaptado de Guarinello e Gregolin (2005, p.138).

No trecho (quadro 1), apresentado de modo a ilustrar um tipo de escrita do surdo, fica bem evidente a necessidade do mediador, seja o bibliotecário ou o professor, ter o domínio de diferentes habilidades e estratégias para lidar com a produção textual do surdo, conforme já sinalizado por Bortolin, Coelho e Araújo (2017). Assim, para a sua efetiva atuação com o leitor surdo, o mediador precisa buscar continuamente a formação complementar, com apoio de educadores, estudiosos e especialistas da leitura e escrita no contexto da surdez.

Ademais, iniciativas por meio de políticas públicas, projetos institucionais e empresariais visando à acessibilidade são (ou deveriam ser)prioridades sociais. A produção científica na área da Educação, principalmente na Educação Especial é abundante, assim como movimentos em defesa da igualdade de oportunidades. Na Ciência da Informação e Biblioteconomia ainda são necessários, além de pesquisas, projetos que possam transformar as unidades de informação em ambientes acessíveis e inclusivos. Neste artigo aborda-se apenas a biblioteca acessível, mas deve-se destacar que há a necessidade de se promover a inclusão também em arquivos e museus.

\section{Biblioteca acessível}

Desde 1975 a Declaração dos Direitos das Pessoas Deficientes garante a elas "[...] o direito inerente de respeito por sua dignidade humana." Porém, historicamente, as barreiras criadas pela sociedade excluíram as pessoas com deficiência de tal forma que o acesso à informação, à arte, à literatura lhes foi negado, não podendo sequer conviver socialmente e de maneira digna. Nega-se também o "[...] direito à educação, ao trabalho produtivo, aos serviços públicos, à recreação e a outras atividades humanas." (ORGANIZAÇÃO DAS NAÇÕES UNIDAS, 1981, p.47).

Uma sociedade acessível, justa e igualitária deve propiciar à todos os indivíduos (sem excluir ninguém) a acessibilidade, isto é, a "[...] inclusão e acesso a locais, produtos, serviços e informação [...] independentemente de capacidades físicas, perceptivas, motoras, culturais e sociais [...]." (SOUZA et al., 2013, p.08).

Quando se trata de acesso à informação, que é um direito dos indivíduos, esbarra-se na instituição biblioteca que dispensa ser apontada como prioridade na vida do cidadão, mas que ainda de fato, pelo menos 
uma parcela das bibliotecas públicas, não conseguiram exercer plenamente seu papel social.Portanto, propiciar o livre acesso à informação

[...] deve ser uma meta a ser perseguida, não por estar em consonância com as políticas públicas (leis, decretos e normas que embasam tais políticas públicas), como também e principalmente por respeitar a dignidade humana das pessoas com deficiência [...]. (CONEGLIAN; SILVA, 2006, p.03).

Da mesma maneira, os acervos de uma biblioteca precisam atender as necessidades do leitor, mas ainda não o fazem, pois, na maioria das bibliotecas inexiste a literatura surda, que abrange livros de histórias em LIBRAS e que é fator de ampliação das possibilidades de leitura para os surdos. Coneglian e Silva (2006, p.06) afirmam que a "[...] tendência é que esse público não seja freqüentador da biblioteca e seus serviços [...]."

Os referidos autores ressaltam que as bibliotecas devem realizar ações apropriadas para os leitores surdos. Ainda que sejam usuários em potencial, a dificuldade da comunicação não pode impedi-los de utilizar esse espaço. A este propósito, ressaltam que a biblioteca não é acessível, então alguns surdos precisam "[...] de terceiros (pessoas ouvintes que possuem conhecimento em Língua de Sinais) para terem acesso a informações." (CONEGLIAN; SILVA, 2006, p.09).

Desse modo, é fundamental que no mínimo uma pessoa que trabalhe na biblioteca seja fluente em Língua de Sinais. O Relatório de Diretrizes para Serviços de Biblioteca para Surdos atenta ao fato de que a surdez é denominada "[...] 'deficiência invisível', porque os surdos não são identificados como surdos pela observação casual e tendem a se mesclar na sociedade." (IFLA, 2000).

Essa invisibilidade faz com que os surdos, muitas vezes permaneçam imperceptíveis na biblioteca, entretanto não se trata de um preconceito por parte dos mediadores, mas o é quando o profissional não procura se inteirar a respeito das deficiências, das diferenças, da acessibilidade (principalmente a acessibilidade atitudinal) e do aprendizado da Língua de Sinais.

Nesse sentido, concorda-se com Barros (2015, p.68) quando afirma que "[...] o desconhecimento de como é o outro provoca o preconceito, isto é, a ideia pré-concebida, acompanhada quase sempre pela suspeita, intolerância ou aversão." A autora acrescenta dizendo que: "Se o desconhecimento pode ser entendido como falta de conhecimento, isto é, estado de ignorância, seu antídoto seria o oposto - conhecer, obter informação para entender melhor o outro e os motivos da aversão." (BARROS, 2015, p.68). Assim, a informação e o conhecimento ajudam a 
romper preconceitos e permitem entender que determinados comportamentos e atitudes são errôneos diante da deficiência e ao conhecê-la caminha-se no sentido do respeito e da tolerância.

O fato da surdez ser concebida como uma diferença e não uma deficiência representa uma conquista para o surdo, "[...] uma nova fase de luta pelo direito à diferença, que reflete também questões políticas, de poder e de inserção social." (SANTANA, 2007, p.33).É importante salientar que ações preconceituosas e injustas contrariam a diversidade de tal forma que "[...] corremos o risco de aderir ou reproduzir em nossa vida pessoal e profissional se não estivermos atentos." (BARROS, 2015, p.68). O maior perigo está na aceitação e no conformismo diante do preconceito e da injustiça,o que, talvez, possa levar os mediadores a agirem da mesma forma, isto é, sem perceber, são coniventes e indiferentes.

Entende-se então, a necessidade de diferentes ações e mediações que possam promover a acessibilidade e a apropriação da leitura pelos surdos. Esse assunto será tratado a seguir.

\section{Mediadores de leitura e o livro de imagem}

A mediação é um dos meios de permitir a acessibilidade, não apenas ao espaço físico, mas à informação e à leitura, valorizando a autonomia e a dignidade do leitor. Ao mesmo tempo em que promove a igualdade, propicia a inclusão na biblioteca.

Como dito, o maior desafio não se encontra nas barreiras físicas, mas nas barreiras comportamentais, as denominadas "barreiras de atitude". (BAPTISTA, 2008). Em outras palavras a acessibilidade não se reduz ao ambiente, mas abrange principalmente as ações "[...] tendo como foco principal a idéia de que todas as pessoas têm direitos e deveres em uma sociedade democrática e que ninguém deve ser excluído por qualquer razão que seja." (BAPTISTA, 2008, p.25).

Por isso, os mediadores da leitura na biblioteca escolar devem estar preparados para atender as crianças com deficiência que "[...] merecem a mesma consideração que os demais, e, portanto, são bem-vindas e desejáveis: entretanto, há que haver tanto constatação quanto preparo para saber lidar com suas capacidades [...]." (BARROS, 2006, p.150). Dessa maneira, acolher as crianças da melhor forma, significa respeitálas, compreender e saber como agir. Além disso, o profissional deve ser flexível e estar "[...] preparado e apto para lutar e exigir que a sua instituição atenda aos dispositivos legais, promova a equiparação de oportunidades, a interação entre pessoas com e sem deficiências [...]." (ALVES; VIGENTIM, 2013, p.13).

A luta por melhores condições de acessibilidade exige preparação e aptidão para lidar com situações reais e cotidianas, mas também requer um profissional responsável, envolvido e comprometido. Ao se referir à 
biblioteca, Barros (2006, p.150) afirma que esta tem um papel e uma responsabilidade diante das pessoas com deficiência ao "[...] atender apropriadamente essa clientela [...] devem ser consideradas suas necessidades universais de aceitação, interação social, estabilidade emocional, independência e estimulação intelectual."

As necessidades universais elencadas pela autora são significativas ao desenvolvimento infantil, principalmente no que se refere à socialização, a emoção e a cognição. Baptista (2008) menciona que a inclusão conduza avaliação de ideias arcaicas, mudara visão de mundo, do eu e do outro. Em se tratando das crianças surdas, Freeman, Carbin e Boese (1999, p.28) defendem que "Só quando conseguimos corrigir nossa percepção [...] e quando encontramos um senso de humanidade compartilhada, é que nossos horizontes podem ser ampliados para incluir a $[\ldots]$ criança surda $[\ldots] . "$

Desse modo, o mediador precisa avaliar sua postura e ações, pois será a sua visão humanista e alteritária que possibilitará a inclusão. Assim como a mediação da leitura e da literatura pode favorecer a inserção das crianças surdas no universo ficcional, tão salutar ao seu desenvolvimento.

O mediador desempenha uma ação essencial porque age "[...] sobre a quantidade, o gosto, o interesse [e] o comportamento do leitor." (PAIVA, 2006, p.258). Vale nesse momento questionar quem é este sujeito? Para Bortolin (2006, p.49) o mediador tem a "[...] função de facilitar o encontro entre o leitor e o texto, cujas ações possam contribuir para a formação e o amadurecimento [...] do mesmo."

Com base nesta definição, o mediador de leitura é o facilitador da relação entre o leitor e o texto pois sua ação fortalece o crescimento do leitor, e assim também, contribui significativamente na formação da criança surda, levando-a ao encontro da literatura podendo utilizar os livros de imagem e realizar a contação de história em Língua de Sinais Aqui vale ressaltar que a Língua de Sinais é "[...] uma língua viso-espacial que se articula por meio das mãos, das expressões faciais e do corpo." (GUARINELLO, 2007, p.51). Enfatiza-se então, que é responsabilidade do mediador adequar sua ação às necessidades dos leitores e no caso da criança surda, o uso da Língua de Sinais é fundamental. Assim

[...] é preciso conhecimento e preparo no trato com [...] leitor ou não-leitor, com capacidades plenas ou não. Por outro lado, o papel do mediador de leitura é promover o melhor encontro entre o texto e o leitor (bem como o leitor em potencial) sem cercá-lo ou limitálo, pois somente os céus podem determinar a altura de cada vôo, quer em sala de aula, quer na biblioteca. (BARROS, 2006, p.154155). 
Os mediadores não devem ignorar a liberdade que está associada ao ato de ler, tampouco desprezar as sensações dele advindas. A eles cabe interferir nesta relação para torná-la cada vez mais agradável, encantadora e surpreendente.Bortolin (2011, p.263) explica que "Um aspecto fundamental [...] é que os mediadores devem [...] descobrir como acontece a recepção de um texto por parte do leitor (seja lendo ou ouvindo)" ou sinalizando a narrativa. Ouvir, no contexto da surdez, é ler por meio do olhar e da Língua de Sinais utilizada pelo mediador/intérprete.

No entender de Silva e Bortolin (2006, p.77) "A literatura é um dos componentes fundamentais no processo de desenvolvimento infantil, pois proporciona à criança resolver seus conflitos internos, além de estimular sua imaginação, contribuindo para que o lúdico esteja presente em sua vida cotidiana." Para tanto, as obras devem ser selecionadas criteriosamente pelo mediador contemplando textos diversos. Nas palavras de Barros (2006, p.148): "[...] a responsabilidade consciente da seleção prévia pelo mediador [...] deve resguardar a questão da individualidade, do interesse particular, do patamar intelectual e cognitivo, da faixa etária mental e cronológica de cada aluno [...]."

O mediador deve direcionar sim, mas não "enclausurar" a leitura. A autora conclui: "O aluno especial merece que se Ihe ofereça uma leitura especial, e não leitura de qualidade duvidosa, por uma escolha aligeirada." (BARROS, 2006, p.148). É importante salientar que o mediador não caminha sozinho na escola e precisa contar com o trabalho de toda equipe pedagógica.

Além de compreender as diferenças, os mediadores precisam contextualizar a leitura e a literatura, que são possibilidades que a criança surda tem de ampliação e de multiplicidade de ideias. Em casa a família também deve participar propiciando o contato com as narrativas. Contudo "[...] em casa, muitas vezes a criança surda não tem acesso aos livros e aos jogos de leitura, o que Ihe dificulta a construção de hipóteses sobre o objeto escrito e a percepção das diferenças entre a escrita e a fala." (GUARINELLO, 2007, p.55).

Nesse sentido, entende-se que os mediadores da leitura podem utilizar o livro de imagem para provocar o olhar e intensificar as emoções da criança surda. Nesse artigo utiliza-se o conceito de Camargo (1995, p.70) de que "Livros de imagem são livros sem texto. As imagens é que contam a história. Os livros com pouco texto, em que o papel principal cabe à ilustração, também podem ser chamados de livros de imagem."Defende-se que a leitura da imagem é primordial, pois é ela que forma "[...] os primeiros conhecimentos da criança, que usa seus sentidos para captar as imagens que a rodeia, compreender seus significados e reagir a elas." (GONDIM; CUNHA; DIAS, 2006, p.17). 
Para ilustrar o conceito de livro de imagem apresenta-se na figura 1 , duas imagens do livro $O$ palhaço voador(1987)de autoria de Rogério Borges. Este livro de imagem compõe a coleção Bons Tempos sendo que a maioria de suas narrativas está disponível no site da Rede de Leitura Mediar, integrando o projeto Livroterapia².

Figura 1 - Livro de Imagem O palhaço voador

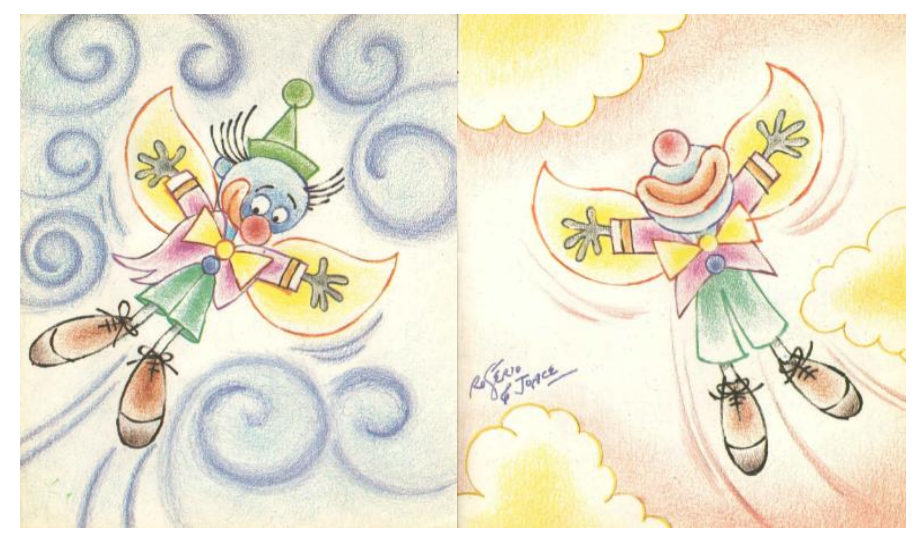

Fonte: Borges (1987).

Como se pode notar o livro de imagem favorece a apropriação da narrativa pela criança surda porque "As ideias ilustradas expressam sentido, colocam em jogo códigos culturais e compõem uma estética apreciável através das situações ilustradas." (PAIVA, 2014, p.47). Na concepção da autora, as imagens transmitem ideias e essas ideias representam culturas; assim também o belo e a arte podem ser explorados, contemplados e mediados pela ilustração.

Os estímulos do livro de imagem podem incentivar a leitura, pois os "Apelos visuais, rítmicos, bem como jogos de cena [...] conseguem provocar o olhar e criar um magnetismo entre livro e leitor, de forma a suscitar que a criança deseje a leitura e o contato com o livro." (PAIVA, 2014, p.49). Ao despertar na criança surda estes desejos pode-se criar um elo indissociável, uma força de aproximação.

Diante do livro de imagem, as reações são as mais diversas, tendo em vista que o leitor "[...] sorri, ri, se espanta, se encanta, olha assim meio bobo porque nunca pensou em nada parecido [...] E fica brincando horas, olhando devagarinho ou depressa, formando e imaginando mil e uma histórias [...]." (ABRAMOVICH, 2001, p.29).

2REDE Mediar. Projeto Livroterapia. nov. 2020. Disponível em:

https://redemediar.wordpress.com/2020/11/13/o-que-e-livroterapia/\#obras-livroterapia.

Acesso em: 17 jun. 2021. 
Com tantas possibilidades, dentre as quais se destaca a de olhar, de brincar e de imaginar, o leitor surdo pode ter uma nova experiência de leitura conforme suas percepções e seu ponto de vista. Quando levado para a sala de aula, o livro de imagem pode "[...] ampliar o repertório dos alunos não somente no que diz respeito à origem de autores, ilustradores e temas, mas [...] ampliar o senso estético e a curiosidade por livros [...]." (PAIVA, 2014, p.46).

Pereira (2016) em pesquisa de Iniciação Científica (IC) financiada pelo Conselho Nacional de Desenvolvimento Científico e Tecnológico (CNPq) cujo título foi Mediação com livros de imagem localizou 344 livros sem texto publicados e comercializados em terras brasileiras. Desde então outros títulos foram lançados e isso demonstra uma parcela do amplo acervo disponível ao mediador de leitura.Acredita-se que além de contribuir na ampliação da percepção estética dos leitores surdos, isto é, na contemplação do belo, os livros de imagem permitem que eles interpretem a narrativa a seu modo, pois "As imagens [...] exigem decifrações e sentimentos. Muitas vezes podem inclusive provocar uma necessidade intensa de interpretação [...]" (PAIVA, 2014, p.45) e, possivelmente de novas leituras. Os questionamentos suscitados pela imagem podem levar a criança surda para um rico "encontro" com a literatura, além de possibilitar a sua autonomia e favorecer a criatividade.

\section{Considerações finais}

A Língua de Sinais é fundamental para o desenvolvimento do surdo. O mediador de leitura precisa dominá-la para poder se comunicar e atrair os seus leitores, portanto, quanto maior o número de mediadores com fluência, maior será a quantidade de serviços oferecidos aos surdos, por exemplo, em uma biblioteca.

O livro de imagem tem se mostrado eficaz ao favorecer o imaginário da criança surda, possibilitando que ela sinalize um texto literário em Língua de Sinais, desenvolvendo assim o letramento visual ao observar os detalhes da ilustração e interpretar a história, além de contemplar a imagem, os traços, conhecer os ilustradores, aprender novos sinais e novas palavras.

A biblioteca e o mediador de leitura, junto com o acervo e serviços oferecidos, podem ser aliados no processo de ensino e aprendizagem da leitura e da escrita das crianças surdas. É preciso que tais reflexões estejam presentes na formação inicial e continuada dos professores (Pedagogia e Letras), bem como na dos profissionais da informação, em especial do bibliotecário.

\section{Referências}

ABRAMOVICH, F. Literatura infantil: gostosuras e bobices. 5. ed. São Paulo: Scipione, 2001. 
ALVES, A. P. M.; VIGENTIM, U. D. Mediação da informação e acessibilidade: a função social do profissional da informação para a inclusão e reconhecimento político das diferenças. In:CONGRESSO BRASILEIRO DE BIBLIOTECONOMIA, DOCUMENTAÇÃO E CIÊNCIA DA INFORMAÇÃO, 25.,2013, Florianópolis. Anais [...]Florianópolis: UFSC, 2013. Disponível em:

http://portal.febab.org.br/anais/article/view/1630/1631. Acesso em: 14 jul. 2021.

BAPTISTA, M. I. S. D. Convivendo com as diferenças. In: PUPO, D. T.; MELO, A. M.; FERRÉS, S. P. (org.). Acessibilidade: discurso e prática no cotidiano das bibliotecas. Campinas: Unicamp, 2008. p.24-27.

BARROS, M. H. T. C. de. De leitura, classes especiais e bibliotecas escolares. In: BARROS, M. H. T. C. de; BORTOLIN, S.; SILVA, R. J. da. Leitura: mediação e mediador. São Paulo: Ed. FA, 2006. p.147-155.

BARROS, M. H. T. C. de. Atividades culturais e a inclusão na biblioteca pública. In: SILVA, J. F. M. da (org.). A biblioteca pública em contexto: cultural, econômico, social e tecnológico. Brasília: Thesaurus, 2015. p.6782.

BARROS, M. E. ELiS - Escrita das Línguas de Sinais: proposta teórica e verificação prática.2008. 196 f. Tese (Doutorado em Linguística) Universidade Federal de Santa Catarina, Florianópolis, 2008. Disponível em:

https://repositorio.ufsc.br/bitstream/handle/123456789/91819/249018.p df? sequence $=1$ \&isAllowed=y. Acesso em: 14 jun. 2021.

BORGES, R. O palhaço voador. Porto Alegre: Kuarup, 1987.

BORTOLIN, S. A leitura literária em suportes eletrônicos na biblioteca infanto-juvenil. In: BARROS, M. H. T. C.; BORTOLIN, S.; SILVA, R. J. da (org.). Leitura: mediação e mediador. São Paulo: Ed. FA, 2006. p.49-64.

BORTOLIN, S. Mediação Oral da Literatura e a Estética da Recepção. Revista EDICIC, v.1, n.3, p.263-276, jul./set. 2011.

BORTOLIN, S.; COELHO, C. D. ; ARAUJO, L. M. Mediação literária em biblioteca infantil. In: CONGRESSO INTERNACIONAL DE LITERATURA INFANTOJUVENIL, 20., 2017. Presidente Prudente.Anais [...] Presidente Prudente: Unesp, 2017. p. 1870-1881.

CAMARGO, L. Ilustração do livro infantil. Belo Horizonte: Editora Lê, 1995. 
CAPOVILLA, F. C. ; VIGGIANO, K. Q. F.; RAPHAEL, W. D. ; NEVES, S. L. G. ; MAURICIO, A. ; VIEIRA, R. ; SUTTON, V. A escrita visual direta de sinais SignW riting e seu lugar na educação da criança surda. In: CAPOVILLA, F. C. ; RAPHAEL, W. D. (org.).Dicionário Enciclopédico Ilustrado Trilíngüe da Língua de Sinais Brasileira: Sinais de M a Z. São Paulo: Editora da Universidade de São Paulo, 2001. v. 2, p. 1491-1516.

CONEGLIAN, A. L. O.; SILVA, H. de C. Biblioteca inclusiva: perspectivas internacionais para o atendimento a usuários com surdez. In: ENCONTRO NACIONAL DE PESQUISA EM CIÊNCIA DA INFORMAÇÃO, 7., 2006, Marília. Anais [...] Marília: ANCIB, 2006. Disponível em:

http://200.20.0.78/repositorios/bitstream/handle/123456789/1268/Andr $\%$ c3\%a9\%20Luis\%200n\%c3\%b3rio-Coneglian.pdf?sequence $=1$. Acesso em: 14 jun. 2021.

CORRADI, J.A.M. Acessibilidade em ambientes informacionais digitais: uma questão de diferença. São Paulo: Editora Unesp, 2011.

COSTA, A. C. C.; SANTOS NETO, J. A. dos. O bibliotecário escolar e a mediação da leitura com livro de imagem. Revista Brasileira de

Biblioteconomia e Documentação, São Paulo, v. 15, n. 1, p. 194-212, jan. 2019. Disponível em: https://rbbd.febab.org.br/rbbd/article/view/1164.

Acesso em: 14 jun. 2021.

DOMINGUES, F.; ALVES, G. F.; FACHIN, G. R. B.; HILLESHEIM, A. I. de A. $\mathrm{O}$ ato de ler para alunos da educação especial. Extensio: Revista

Eletrônica de Extensão, Florianópolis, v.3, n.4, p. 1-10, ago. 2008.

Disponível em:

https://periodicos.ufsc.br/index.php/extensio/article/view/5569/5068.

Acesso em: 14 jun. 2021.

FREEMAN, R. D. ; CARBIN, C. F. ; BOESE, R. J. Seu filho não escuta? um guia para todos que lidam com crianças surdas. Brasília: Coordenadoria Nacional para Integração da Pessoa Portadora de Deficiência, 1999.

GESSER, A. Libras? Que língua é essa? Crenças e preconceitos em torno da língua de sinais e da realidade surda. São Paulo: Parábola Editorial, 2009.

GONDIM, M. M. R.; CUNHA, M. A. A.; DIAS, S. A. P. W. Linguagens e códigos. In: MENEZES, M. B. de; RAMOS, W. M. (org.). Livro de estudo: Módulo IV. Brasília: MEC, 2006. Disponível em: http://portaldoprofessor.mec.gov.br/storage/materiais/0000012792.pdf. Acesso em: 14 jun. 2021.

GUARINELLO, A. C. O papel do outro na escrita de sujeitos surdos. São Paulo: Plexus, 2007. 
GUARINELLO, A.C.; GREGOLIN, R.M. As produções escritas de sujeitos surdos. Revista Letras, Curitiba, n. 65, p. 135-151, jan./abr. 2005. Disponível em: https://revistas.ufpr.br/letras/article/view/4317/3810. Acesso em: 14 jun. 2021.

INTERNATIONAL FEDERATION OF LIBRARY ASSOCIATIONS AND INSTITUTIONS. [IFLA]. Relatório Diretrizes para Serviços de Biblioteca para Surdos. 2000.

LIMA, T.C.S.; MIOTO, R.G.T. Procedimentos metodológicos na construção do conhecimento científico: a pesquisa bibliográfica. Revista Katálysis, Florianópolis, v. 10, n. esp., p. 37-45, 2007. Disponível em: https://periodicos.ufsc.br/index.php/katalysis/article/view/S1414 49802007000300004. Acesso em: 14 jun. 2021.

ORGANIZAÇÃO DAS NAÇÕES UNIDAS (ONU). Relatório do Ano Internacional das Pessoas Deficientes. 1981. Disponível em: https://www.livrosgratis.com.br/ler-livro-online-6806/ano-internacionaldas-pessoas-deficientes---1981. Acesso em: 14 jun. 2021.

ORGANIZAÇÃO DAS NAÇÕES UNIDAS (ONU). Declaração dos Direitos das Pessoas Deficientes. 1975. Disponível em: http://portal.mec.gov.br/seesp/arquivos/pdf/dec_def.pdf. Acesso em: 14 jun. 2021.

PAIVA, A. Estatuto literário e escola. In: EVANGELISTA, A. A. M.; BRANDÃO, H. M. B.; MACHADO, M. Z. V. (org.). A escolarização da leitura literária: o jogo do livro infantil e juvenil. 2. ed. Belo Horizonte: Autêntica, 2006.

PAIVA, A. P. Livros de imagem: como aproveitar a atratividade e desenvolver o potencial destas obras na sala de aula com atividades literárias. In: Literatura fora da caixa. Brasília: Ministério da Educação, Secretaria de Educação Básica, 2014. v. 3, p. 43-58.

PEREIRA, A. P. Mediação da leitura com livros de imagem. 2016. Relatório Final de Projeto de Iniciação Científica (Graduação em Biblioteconomia) Universidade Estadual de Londrina, Londrina, 2016.

PEREIRA, S. de L. Ambientes digitais Informacionais para surdos: uma análise dos sites de bibliotecas universitárias federais brasileiras. $116 \mathrm{f}$. Monografia (Graduação em Biblioteconomia) - Universidade de Brasília, Brasília, 2018. Disponível em: https://bdm.unb.br/handle/10483/20890. Acesso em: 15 jun. 2021. 
SANTANA, A. P. Surdez e linguagem: aspectos e implicações neurolingüísticas. São Paulo: Plexus, 2007.

SILVA, R. J. da; BORTOLIN, S. Das prateleiras às mãos. In: BARROS, M. H. T. C. de; BORTOLIN, S.; SILVA, R. J. da. (org.). Leitura: mediação e mediador. São Paulo: Ed. FA, 2006. p.75-88.

SKLIAR, C. Educação \& Exclusão: abordagens sócio-antropológicas em Educação Especial. 2. ed. Porto Alegre: Mediação, 2000.

SKLIAR, C. (org.). A surdez: um olhar sobre as diferenças. Porto Alegre: Mediação, 1998.

SOUZA, M. S. de; COSTA, M. de F. O.; TABOSA, H. R.; ARARIPE, F. M. A. Acessibilidade e inclusão informacional. Informação \& Informação, Londrina, v.18, n.1, p. 01-16, jan./abr. 2013. Disponível em: https://www.researchgate.net/publication/264496127 Acessibilidade e in clusao informacional. Acesso em: 15 jun. 2021. 